\title{
Basic Gene Expression Characteristics of Glioma Stem Cells and Human Glioblastoma
}

\author{
DAISUKE SAKAMOTO ${ }^{1}$, TOSHINORI TAKAGI ${ }^{1}$, MITSUGU FUJITA $^{2}$, SEIICHI OMURA ${ }^{2}$, \\ YASUNORI YOSHIDA ${ }^{1}$, TOMOKO IIDA ${ }^{1}$ and SHINICHI YOSHIMURA ${ }^{1}$ \\ ${ }^{1}$ Department of Neurosurgery, Hyogo College of Medicine, Hyogo, Japan; \\ ${ }^{2}$ Department of Microbiology, Faculty of Medicine, Kindai University, Osaka, Japan
}

\begin{abstract}
Background: Glioma stem cells (GSCs) play important roles in the tumorigenesis of glioblastoma multiforme $(G B M)$. Using a novel cellular bioinformatics pipeline, we aimed to characterize the differences in gene-expression profiles among GSCs, U251 (glioma cell line), and a human GBM tissue sample. Materials and Methods: Total RNA was extracted from GSCs, U251 and GBM and microarray analysis was performed; the data were then applied to the bioinformatics pipeline consisting of a principal component analysis (PCA) with factor loadings, an intracellular pathway analysis, and an immunopathway analysis. Results: The PCA clearly distinguished the three groups. The factor loadings of the PCA suggested that v-myc avian myelocytomatosis viral oncogene neuroblastoma derived homolog (MYCN), dipeptidyl-peptidase 4 (DPP4), and macrophage migration-inhibitory factor (MIF) contribute to the stemness of GSCs. The intracellular pathway and immunopathway analyses provided relevant information about the functions of representative genes in GSCs. Conclusion: The newly-developed cellular bioinformatics pipeline was a useful method to clarify the similarities and differences among samples.
\end{abstract}

Glioblastoma multiforme (GBM) is an aggressive malignant brain tumor conferring a mean progression-free survival of 7 months and a mean overall survival of 15 months, even with multimodal treatment including surgery, temozolomide-based chemotherapy, and radiation therapy (1). Its poor prognosis is attributable to limited surgical resection due to massive

Correspondence to: Mitsugu Fujita, Department of Microbiology, Faculty of Medicine, Kindai University, 377-2 Onohigashi Sayama, Osaka, Japan. E-mail: mfujita47@gmail.com and Shinichi Yoshimura, Department of Neurosurgery, Hyogo College of Medicine, 1-1 Mukogawa-cho Nishinomiya, Hyogo, Japan. E-mail: hyogoneuro@yahoo.co.jp

Key Words: Glioblastoma, glioma stem cell, cell line, stemness, factor loading. infiltration into the brain parenchyma, drug resistance due to genetic or epigenetic alterations, and radiation resistance (2). Consequently, recurrence inevitably occurs. Recent studies have identified glioma stem cells (GSCs) in glioma tissues and have suggested their important roles in GBM (3). For instance, GSCs exhibit pluripotency, which is responsible for the heterogeneity and invasive pathogenicity of GBM (4). They also express multidrug transporters at high levels, which explains the drug resistance of glioma (5). Moreover, GSCs possess DNA repair ability, which induces radiation resistance (6). In addition, because they possess the ability to self-renew, they form microspheres in vitro and tumor masses in vivo that recapitulate the original tumors $(7,8)$. Based on these findings, GSCs have drawn attention as a new therapeutic target for GBM (9).

Multiomics technologies, such as genomics, proteomics and metabolomics, have recently been applied in the field of cancer research, including brain tumor research (10). These molecular biological techniques have identified the genetic and epigenetic alterations in GBM, such as methylation of the $O^{6}$-methylguanine methyltransferase $(M G M T)$ promotor (11) and isocitrate dehydrogenase $(I D H)$ mutations (12), both of which are considered prognostic markers of GBM. In particular, the $I D H$ mutation status has been integrated into the most recent World Health Organization Classification of Tumors of the Central Nervous System (13). Furthermore, the Cancer Genome Atlas project has reported that the receptor tyrosine kinase resistance to audiogenic seizures (RAS)-phosphatidylinositol 3-kinase (PI3K) pathway, p53 pathway, and retinoblastoma protein pathway are important signaling pathways in GBM (14). Molecular biological techniques have elucidated other important characteristics of GBM, including histone modifications involved in transcriptomic changes induced by hypoxic stress (15), microRNAs that further regulate gene expression $(16,17)$, and altered immune responses, such as tumor-associated microglia/macrophages involved in tumor proliferation, survival, and migration (18). However, these techniques have not yet been well-organized as transomics technologies. 
In GSC research, culture techniques have been developed to isolate and maintain GSCs from GBM tissues. However, these conventional GSCs are unable to proliferate or survive after several passages. In this regard, several GSC lines have been established recently $(19,20)$. These GSC lines have resolved the issues associated with conventional GSCs. Nevertheless, differences in gene-expression profiles between these GSC lines and fresh human GBM tissues have not been evaluated. To this end, we established a novel cellular bioinformatics pipeline consisting of a principal component analysis (PCA) with factor loading, intracellular pathway analysis, and immunological pathway analysis using microarray data. With this pipeline, we comprehensively evaluated the differences in gene-expression profiles among GSCs, the glioma cell line U251, and GBM sample, and elucidated factors that are specifically associated with GSCs.

\section{Materials and Methods}

Patients and cell lines. This study was approved by the Ethics Committee of Hyogo College of Medicine (Approval number: 363). Upon the acquisition of written-informed consent from a patient with GBM, a GBM tissue sample was obtained by direct tumor resection at Hyogo College of Medicine. The patient was a 54-yearold female. Her integrated molecular pathological diagnosis was glioblastoma, $I D H$ wild-type. Human GSC lines X01 and X03 were kindly provided by Dr. Akio Soeda at Gifu University $(20,21)$. The human GBM cell line U251 was purchased from the Japanese Collection of Research Bioresources Cell Bank (Osaka, Japan).

Cell cultures. Tumor sphere cultures were prepared as described previously $(20,21)$, with some modifications, in Dulbecco's modified Eagle's medium-F12 (Gibco-Invitrogen, La Jolla, CA, USA) containing penicillin G, streptomycin sulfate, B-27 (GibcoInvitrogen), recombinant human epidermal growth factor $(20 \mathrm{ng} / \mathrm{ml}$; R\&D Systems, Minneapolis, MN, USA), and recombinant human fibroblast growth factor $2(20 \mathrm{ng} / \mathrm{ml}$; R\&D Systems). Cells were cultured in Heracell $\mathrm{CO}_{2}$ incubators (Thermo Fisher Scientific, Asheville, NC, USA) at $37^{\circ} \mathrm{C}, \geq 95 \%$ relative humidity, and $5 \% \mathrm{CO}_{2}$ under $20 \%$ oxygen conditions. The human glioma cell line U251 was maintained in Dulbecco's modified Eagle's medium (Sigma-Aldrich, Milan, Italy) containing $10 \%$ fetal bovine serum, $1 \%$ penicillin $\mathrm{G}$, and streptomycin sulfate. Cells were grown at $37^{\circ} \mathrm{C}$ in $5 \% \mathrm{CO}_{2}$ in humidified atmospheric conditions for 6 days and were enzymatically dissociated using $0.25 \%$ trypsin and $0.02 \%$ EDTA solution.

RNA extraction and oligonucleotide microarray. The procedure used in this study has been reported previously (22). Briefly, total RNA was extracted from the GSC and U251 lines, and the GBM tissue sample and purified using Qiagen RNeasy Mini Kit (QIAGEN N.V., Venlo, the Netherlands) according to the manufacturer's instructions. Biotinylated cRNA was synthesized from 250 ng of total RNA using GeneChip 3' IVT PLUS Reagent Kit (Thermo Fisher Scientific) according to the manufacturer's instructions. The biotinylated cRNA yield was determined using the NanoDrop 2000 Spectrophotometer (Thermo Fisher Scientific). Subsequently, $15 \mu \mathrm{g}$ of cRNA was hybridized for $16 \mathrm{~h}$ at $45^{\circ} \mathrm{C}$ on the GeneChip Human Genome U133 Plus 2.0 Array (Thermo Fisher Scientific). The array was washed, stained with phycoerythrin-labeled streptavidin using the GeneChip Fluidics Station 450 (Thermo Fisher Scientific), and scanned using GeneChip Scanner 3000 7G (Thermo Fisher Scientific). A single array analysis was conducted using Microarray Suite version 5.0 (Thermo Fisher Scientific) with the Thermo Fisher Scientific default settings and the global scaling method to normalize the intensities. The trimmed mean target intensity of each array was arbitrarily set to 500. Simultaneously, the microarray data was deposited in Gene Expression Omnibus (GEO, http://www.ncbi.nlm.nih.gov/geo/); with GEO accession number GSE124145.

Bioinformatics analyses. The NetAffx Library Files of the Human Genome U133 Plus 2.0 Array and the Transcriptome Analysis Console (TAC ver. 4.0; Thermo Fisher Scientific) were used to quantify the signal intensity of each gene. To achieve dimensional compression of the microarray data and evaluate the differences among samples, a principal component analysis (PCA) was performed using R ver. 3.4.1 with the "prcomp" package $(23,24)$. Factor loading for each principal component was used to rank genes that contributed to principal component values.

WikiPathways (http://www.wikipathways.org) is a biology community-maintained web service that is used to visualize biological pathways (25). Each pathway has its own page that contains diagrams, descriptions, references, version histories, component genes, protein lists, etc. In order to explore the differences in biological pathways between the GSCs and GBM, TAC was used to evaluate the statistically enrichment of differentially expressed genes in pathways.

In order to predict immune responses in each sample based on the gene expression data, ImmQuant was used (26). ImmQuant is freely available online (http://csgi.tau.ac.il/ImmQuant/). This software is used to visualize inferred alterations in the composition of immune cell populations in human samples based on microarray data.

Statistical evaluation. The statistical procedures used in this study have been reported previously (22). Significant differences were evaluated using one-way ANOVA on ranks. Significance levels were set at $p<0.05$ and a mean difference of greater than two-fold (27).

\section{Results}

Gene expression patterns of GSCs, U251 and GBM. We first performed microarray-based comprehensive gene-expression analyses of GSCs, U251, and hGBM (Tables I and II). We further evaluated each of these samples for genes that have been reported as major functional factors or major determinants of GBM properties (Figure 1A). GBM and U251 had similar expression patterns of these previously reported genes $(3,28-32)$. In contrast, GSCs exhibited unique expression patterns compared to those of GBM and U251.

In order to clarify the similarities and differences among these samples, we performed a PCA using the geneexpression data (PCA mapping; Figure 1B). The first principal component (PC1; accounting for $41.7 \%$ of the total variance) clearly distinguished the fresh human GBM tissue from the cell lines (U251 and GSCs); it reflected the characteristics of cell lines. The second principal component (PC2; accounting for $18.5 \%$ of the total variance) clearly 
Table I. Top 15 genes found to be highly expressed in glioma stem cells (X01) compared to glioblastoma cell line (U251), sorted by fold-change.

\begin{tabular}{|c|c|c|c|c|}
\hline Gene symbol & Description & $\mathrm{X} 01 \mathrm{Avg}\left(\log _{2}\right)$ & U251 $\operatorname{Avg}\left(\log _{2}\right)$ & Fold change \\
\hline CHI3L1 & Chitinase 3-like 1 (cartilage glycoprotein-39) & 15.23 & 2.01 & 9529.99 \\
\hline$M Y C N$ & v-Myc avian myelocytomatosis viral oncogene neuroblastoma-derived homolog & 14.8 & 2.51 & 5009.87 \\
\hline DPP4 & Dipeptidyl-peptidase 4 & 11.73 & 0.52 & 2369.82 \\
\hline NFIA & Nuclear factor $\mathrm{I} / \mathrm{A}$ & 13.7 & 2.86 & 1840.35 \\
\hline CHI3L1 & Chitinase 3-like 1 (cartilage glycoprotein-39) & 15.2 & 4.47 & 1704.82 \\
\hline SLC6A15 & Solute carrier family 6 (neutral amino acid transporter), member 15 & 11.32 & 1.06 & 1229.06 \\
\hline TIE1 & Tyrosine kinase with immunoglobulin-like and EGF-like domains 1 & 12.34 & 2.25 & 1089.92 \\
\hline CA12 & Carbonic anhydrase XII & 11.37 & 1.5 & 930.51 \\
\hline$R N F 128$ & Ring finger protein $128, \mathrm{E} 3$ ubiquitin protein ligase & 10.69 & 0.96 & 849.21 \\
\hline SOX8 & SRY box 8 & 11.93 & 2.2 & 847.99 \\
\hline DPP4 & Dipeptidyl-peptidase 4 & 11.64 & 1.93 & 836.11 \\
\hline$C D K N 2 C$ & Cyclin-dependent kinase inhibitor 2C (p18, inhibits CDK4) & 13.12 & 3.53 & 769.72 \\
\hline GPR37 & G-Protein-coupled receptor 37 (endothelin receptor type B-like) & 10.99 & 1.56 & 686.72 \\
\hline PCDH19 & Protocadherin 19 & 11.87 & 2.76 & 555.43 \\
\hline GNG4 & Guanine nucleotide binding protein ( $\mathrm{G}$ protein), gamma 4 & 10.86 & 1.82 & 528.13 \\
\hline
\end{tabular}

SRY, Sex determining region Y; EGF, epidermal growth factor.

Table II. Top 15 genes found to be highly expressed in glioma stem cells (X01) compared to human glioblastoma tissue (hGBM) sorted by foldchange.

\begin{tabular}{|c|c|c|c|c|}
\hline Gene symbol & Description & X01 Avg $\left(\log _{2}\right)$ & hGBM Avg $\left(\log _{2}\right)$ & Fold change \\
\hline Undefined & Undefined & 11.81 & 0.19 & 3158.27 \\
\hline Undefined & Undefined & 12.93 & 1.93 & 2042.66 \\
\hline Undefined & Undefined & 11.02 & 0.19 & 1812.64 \\
\hline SLC6A15 & Solute carrier family 6 (neutral amino acid transporter), member 15 & 11.32 & 1.34 & 1015.51 \\
\hline$M Y C N$ & v-Myc avian myelocytomatosis viral oncogene neuroblastoma derived homolog & 10.65 & 1.24 & 676.87 \\
\hline$D P P 4$ & Dipeptidyl-peptidase 4 & 11.64 & 2.41 & 598.94 \\
\hline TRDV3 & T-Cell receptor delta variable 3 & 11.1 & 1.93 & 576.3 \\
\hline Undefined & Undefined & 13.1 & 4.21 & 475.67 \\
\hline Undefined & Undefined & 9.79 & 1.52 & 308.87 \\
\hline Undefined & Undefined & 9.59 & 1.66 & 243.59 \\
\hline C6orf15 & Chromosome 6 open reading frame 15 & 12.45 & 4.74 & 209.89 \\
\hline$M Y C N$ & v-Myc avian myelocytomatosis viral oncogene neuroblastoma-derived homolog & 11.27 & 3.99 & 155.99 \\
\hline RASEF & RAS and EF-hand domain containing & 10.54 & 3.29 & 152.3 \\
\hline$Y M E 1 L 1$ & YME1-like 1 ATPase & 10.14 & 3.31 & 113.82 \\
\hline SLC6A15 & Solute carrier family 6 (neutral amino acid transporter), member 15 & 9.09 & 2.28 & 112.4 \\
\hline
\end{tabular}

RAS, Resistance to audiogenic seizures; YME, yeast mitochondrial escape; ATPase, adenosine triphosphatase.

distinguished GSCs from GBM and U251; it reflected the characteristics of stemness.

Factor loadings and pathway analysis revealed representative factors in GSCs. Next, we evaluated factor loadings for each principal component in order to identify contributing factors (Figure 2). The factor loading for PC1 (Figure 2A) suggested that the expression of engulfment adaptor 1 (GULPl), transcriptional coactivator and phosphatase 4 (EYA4), serine/threonine kinase 26 (STK26), and semaphorin 3A (SEMA3A) would positively contribute to differences between cell lines (GSCs and U251) and tissue-derived materials (GBM). The factor loading for PC2 (Figure 2B) suggested that the expression of $\mathrm{v}$-myc avian myelocytomatosis viral oncogene neuroblastoma derived homolog $(M Y C N)$, dipeptidyl-peptidase 4 (DPP4), and macrophage migration-inhibitory factor (MIF) would contribute to the stemness of GSCs.

Based on these findings, we hypothesized that PC2-related genes were important in identifying representative factors that distinguish GSCs from other cells in glioma tissues. Therefore, we performed an intracellular pathway analysis for the PC2related genes using WikiPathway. MYCN was found to be 
A

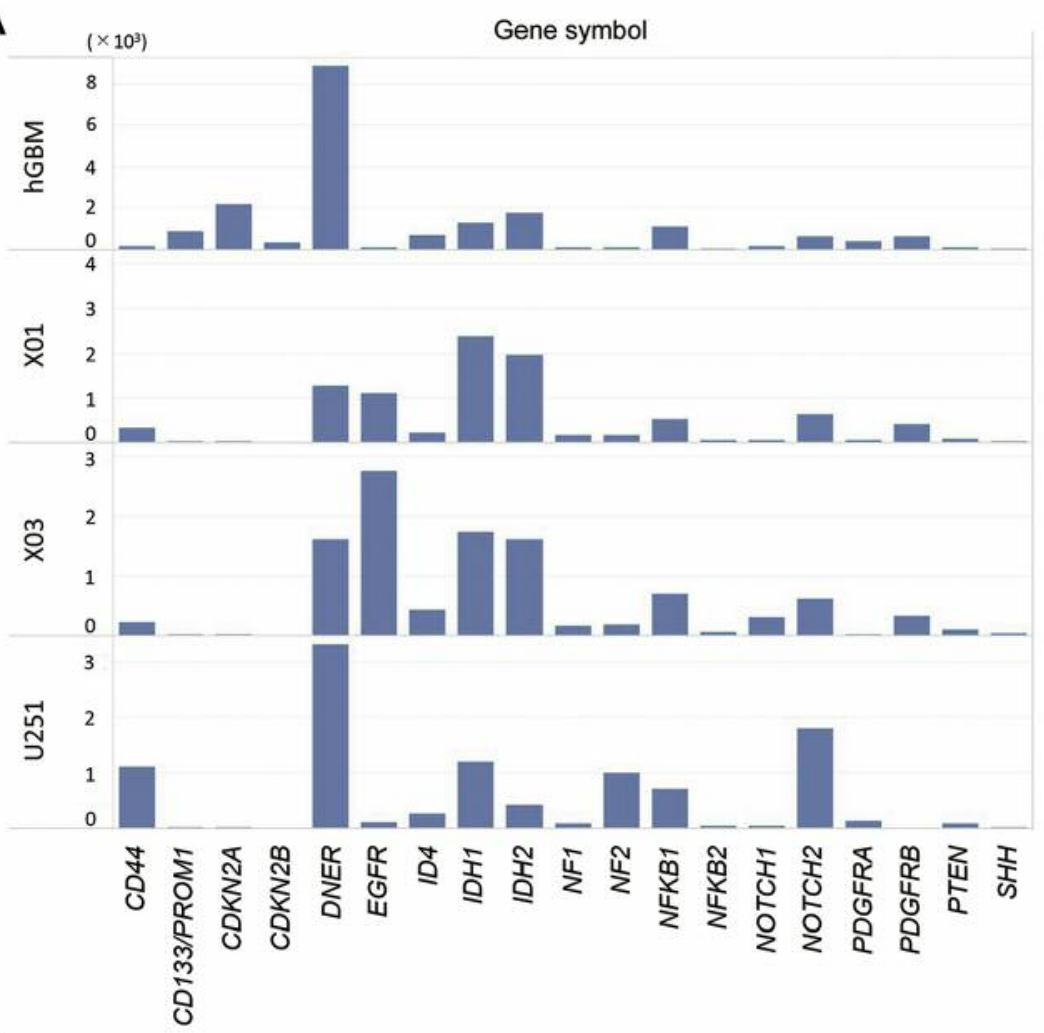

B

PCA Mapping $71.4 \%$ (CHP)

PCA2 $18.5 \%$

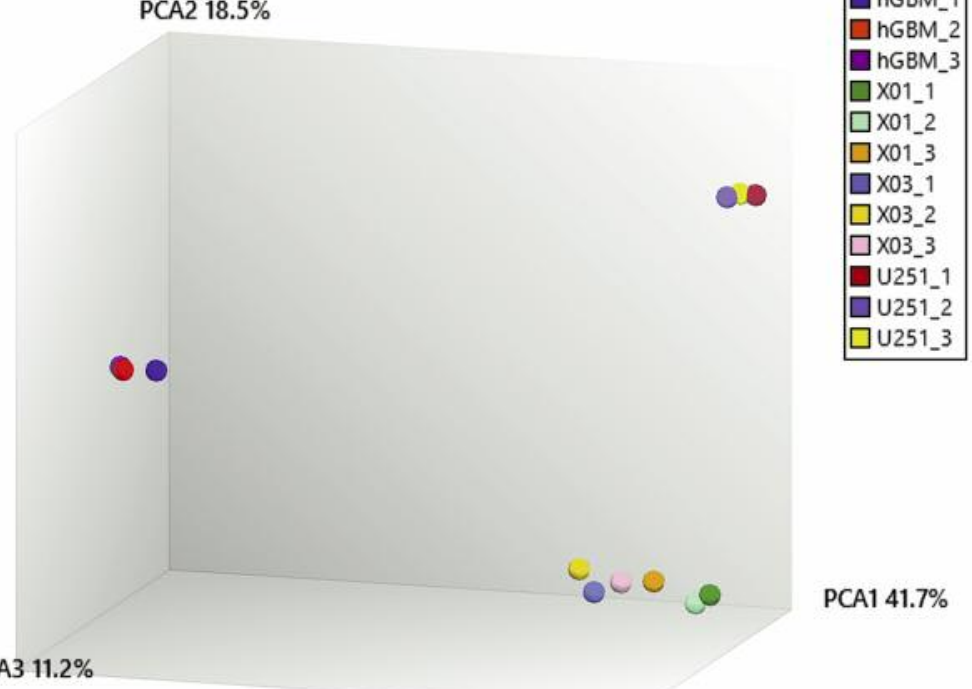

Figure 1. Genetic characterization of the glioblastoma (GBM) the cell line U251, the X01 and X03 glioma stem cell (GSC) lines, and human (h)GBM tissues. A: Expression patterns of genes previously reported as major factors of GBM. B: Principal component analysis (PCA) mapping based on the gene-expression levels of U251, X01, and X03 GSCs and hGBM. The first principal component $(P C 1 ; 41.7 \%)$ reflects the characteristics of cell lines. The GSC cell line and GBM cell line were separated along the second principal component (PC2; 18.5\%), indicating the stemness characteristics. CD44, CD44 molecule; CD133/PROM1, prominin 1; CDKN2A, cyclin-dependent kinase inhibitor 2A; DNER, delta/notch-like EGF repeat containing; EGFR, epidermal growth factor receptor; ID4, inhibitor of DNA binding 4; IDH1, isocitrate dehydrogenase [NADP(+)]1 cytosolic; IDH2, isocitrate dehydrogenase [NADP(+)]2, mitochondrial; NF1, neurofibromin 1; NF2, neurofibromin 2; NFKB1, nuclear factor kappa B subunit 1; NFKB2, nuclear factor kappa B subunit 2; NOTCH1, notch 1; NOTCH2, notch 2; PDGFRA, platelet-derived growth factor receptor alpha; PDGFRB, platelet-derived growth factor receptor beta; PTEN, phosphatase and tensin homolog; SHH, sonic hedgehog signaling molecule; PC3, third principal component. 

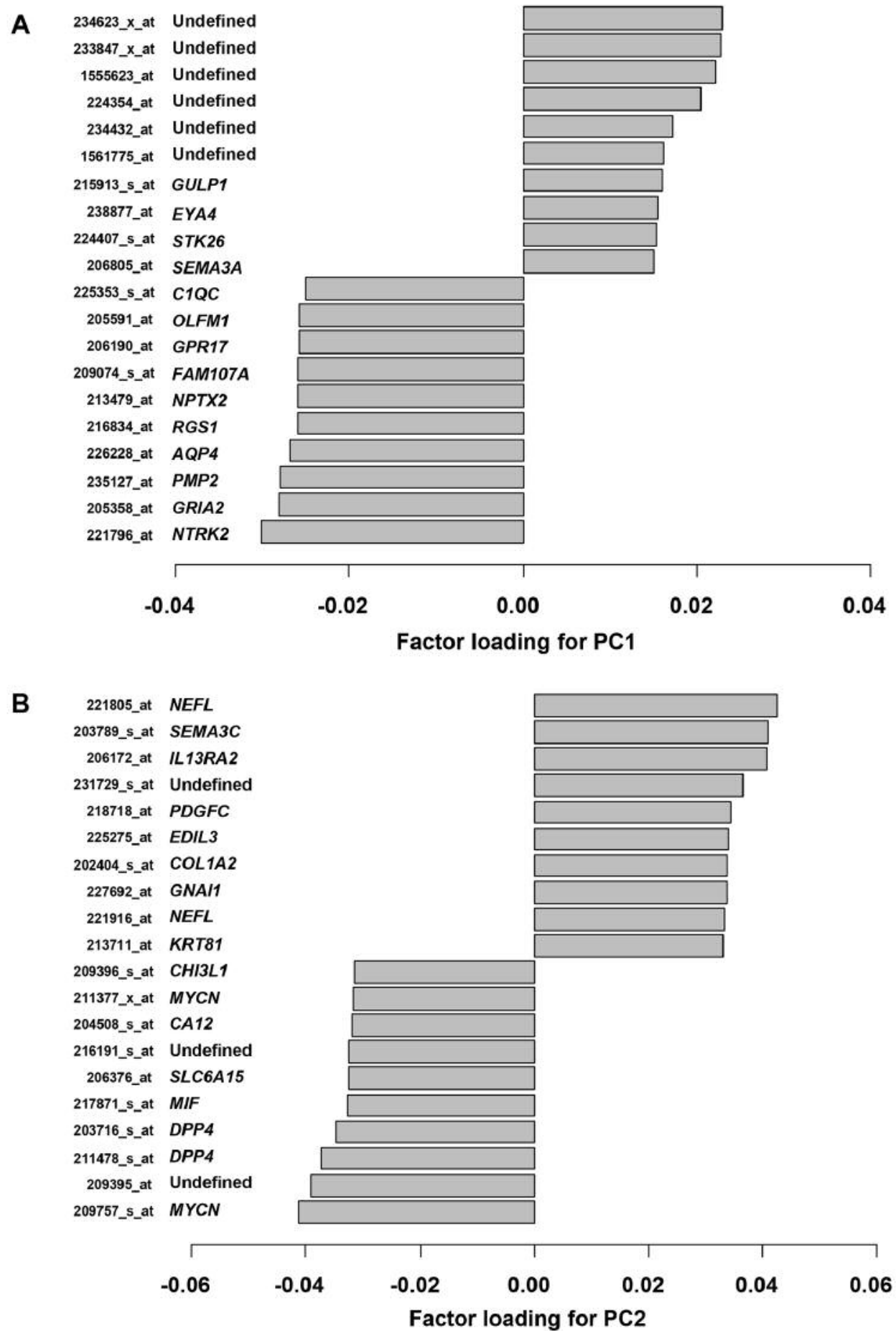

Figure 2. Principal component analysis-based factor loading. A: Representative factors contributing to principal component PC1. B: Representative factors contributing to PC2. GULP1, Engulfment adaptor 1; EYA4, transcriptional coactivator and phosphatase 4; STK26, serine/threonine kinase 26; SEMA3A, semaphorin 3A; C1QC, complement C1q C chain; OLFM1, olfactomedin 1; GPR17, G-protein-coupled receptor 17; FAM107A, family with sequence similarity 107 member A; NPTX2 neuronal pentraxin 2; RGS1, regulator of G protein signaling 1; AQP4, aquaporin 4; PMP2, peripheral myelin protein 2; GRIA2, glutamate ionotropic receptor AMPA type subunit 2; NTRK2, neurotrophic receptor tyrosine kinase 2; NEFL, neurofilament light; SEMA3C, semaphorin 3C; IL13RA2, interleukin 13 receptor subunit alpha 2; PDGFC, platelet-derived growth factor C; EDIL3, EGF like repeats and discoidin domains 3; COL1A2, collagen type I alpha 2 chain; GNAI1, G protein subunit alpha i1; KRT81, keratin 81; CHI3L1, chitinase 3-like 1; MYCN, v-myc avian myelocytomatosis viral oncogene neuroblastoma derived homolog; CA12, carbonic anhydrase 12; SLC6A15, solute carrier family 6 member 15; MIF, macrophage migration inhibitory factor; DPP4, dipeptidyl-peptidase 4; PC2, second principal component. 


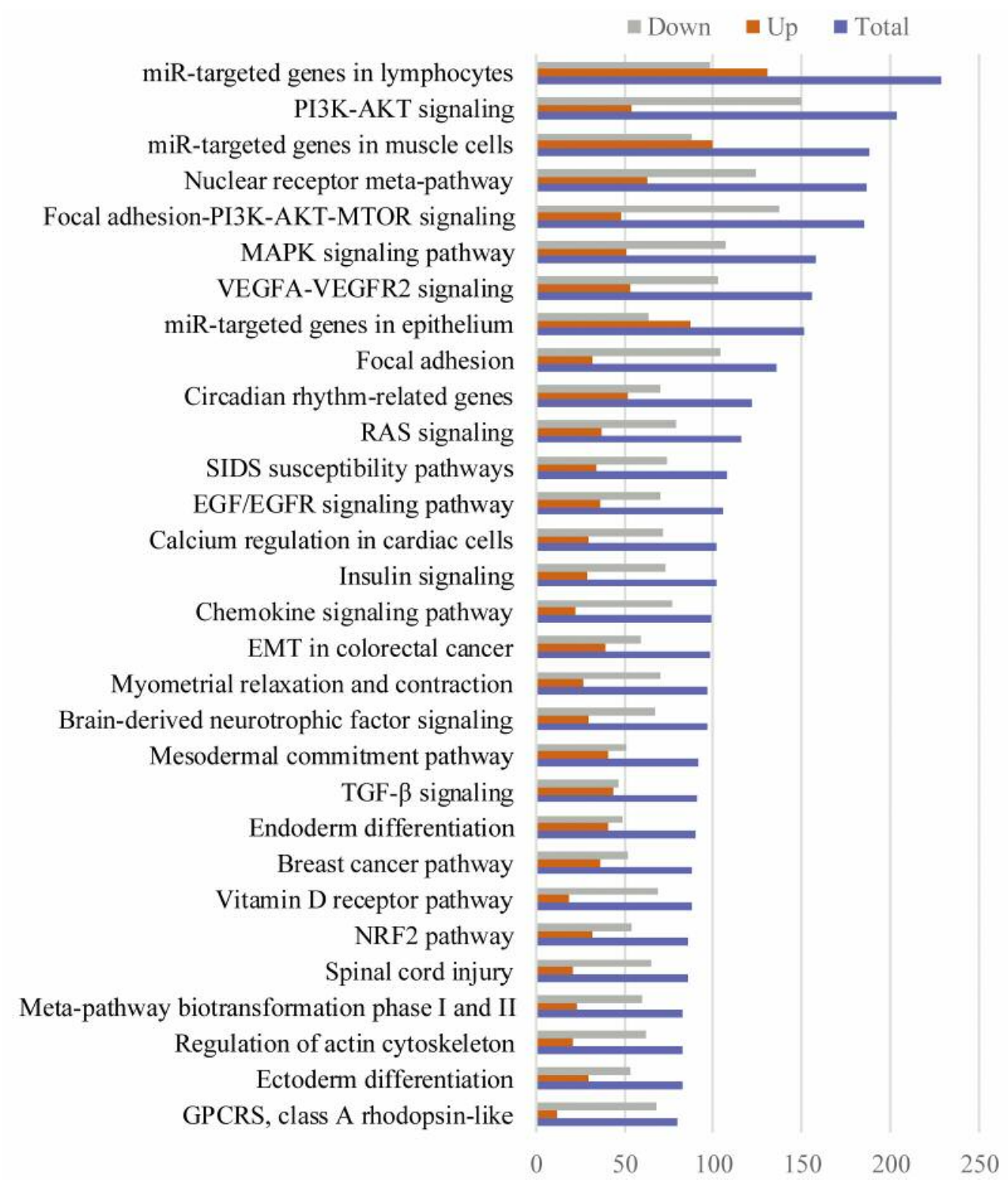

Figure 3. Bar graph indicating the top 30 pathways enriched in glioma stem cells (GSCs) compared with human glioblastoma tissue (hGBM). Down: Gene sets reduced in GSCs compared with hGBM; Up: gene sets increased in GSCs compared with hGBM; Total: the sum of changes in gene sets in GSCs against hGBM. PI3K-AKT, Phosphatidylinositol-3 kinase-serinelthreonine kinase; MTOR, mechanistic target of rapamycin kinase; MAPK, mitogen-activated protein kinase; VEGFA, vascular endothelial growth factor A; VEGFR2, kinase insert domain receptor; RAS, resistance to audiogenic seizures; SIDS, sudden infant death syndrome; EGF/EGFR, epidermal growth factor/epidermal growth factor receptor; EMT, epithelial to mesenchymal transition; TGF- $\beta$, transforming growth factor beta; NRF2, nuclear factor, erythroid 2 like 2; GPCRS, G protein-coupled receptors.

involved in the pathway miR target genes in lymphocytes (Figure 3). In addition, solute carrier family 6 member 15 (SLC6A15) was associated with the NRF2 pathway (Figure 3), and collagen type I alpha 2 chain (COL1A2) and platelet derived growth factor $\mathrm{C}$ ( $P D G F C)$ with the Focal adhesion pathway (Figure 3). These data suggest that the representative factors for GSC identification in tissues were related to cell proliferation, cell survival, glucose supply, immunesuppression, anti-oxidative stress, and migration.

GSCs expressed macrophage-inhibitory factors but macrophage inhibition was not detected by an ImmQuant analysis. Two factors in the factor loading for PC2 were associated with immune responses [Figure 2B: MIF 


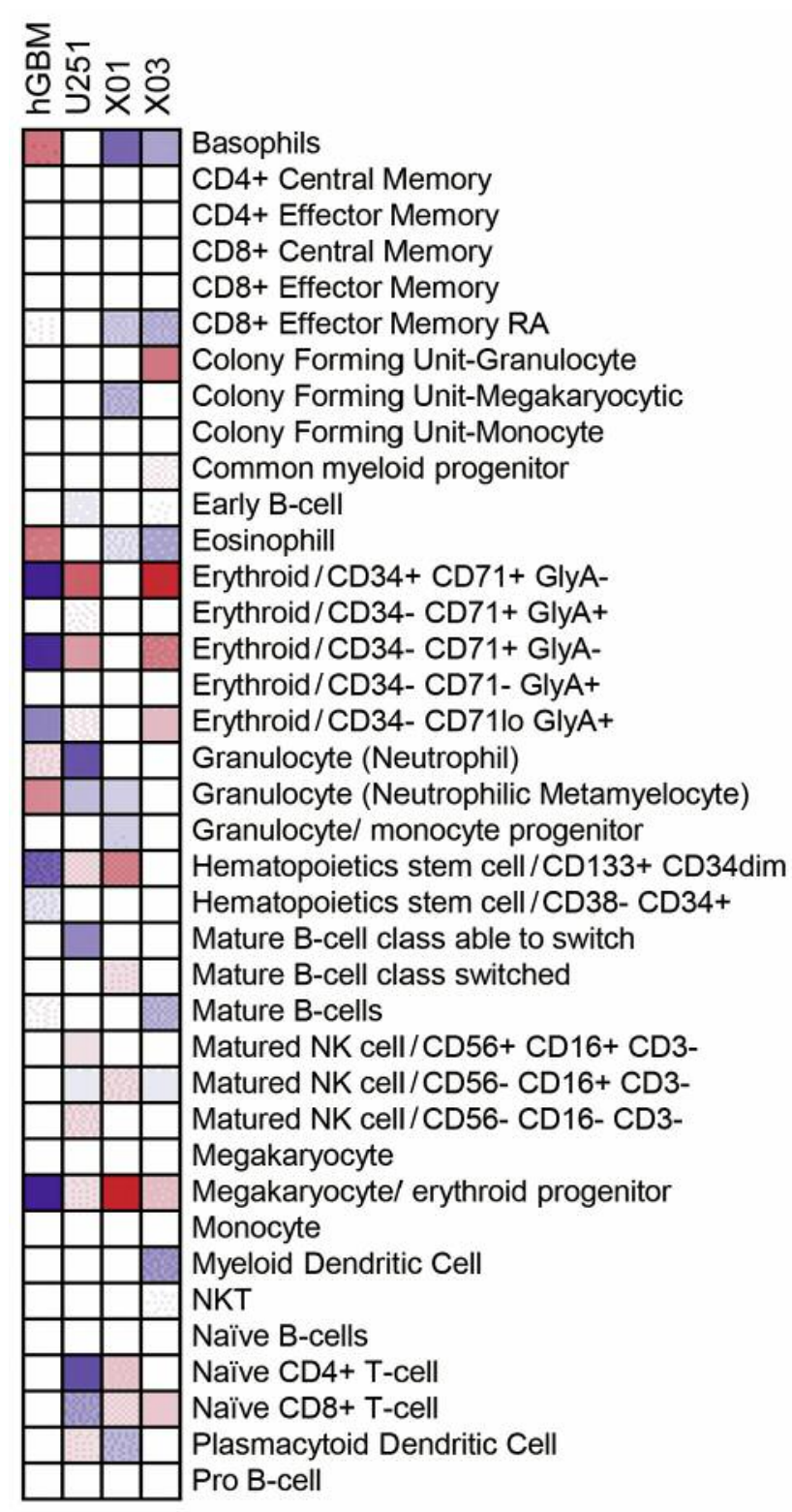

Figure 4. Matrix indicating possible kinetics of immune cells based on ImmQuant analyses. Red: Increased, blue; decreased. Mature NK cell, mature natural killer cell; NKT, natural killer T-cell.

(positive association) and $P D G F C$ (negative association)]. Based on these findings, an ImmQuant analysis was performed to evaluate the association of GSCs with the immune system. We detected increases in neutrophilic metamyelocytes, neutrophils, naïve $\mathrm{CD}^{+} \mathrm{T}$-cells, and naïve $\mathrm{CD} 8^{+} \mathrm{T}$-cells (Figure 4). However, there were no differences among factors relevant to macrophages, natural killer cells, or dendritic cells.

\section{Discussion}

In the present study, we established a method for evaluating cell type-specific gene expression as well as the representative factors, pathways, and associated immune responses. We used this method to comprehensively analyze GSCs, U251, and GBM using microarray data (Tables I and II). A PCA demonstrated substantial differences in gene expression patterns among GSCs, U251, and GBM (Figure 1). The factor loadings revealed 14 genes to be representative factors contributing to the stemness of GSCs (Figure 2). Based on a pathway analysis, the representative factors identified by the PCA were associated with cell proliferation (MYCN and DPP4), glucose metabolism (DPP4), antioxidative stress (SLC6A15), and the suppression of cell adhesion (COL1A2; Figure 3). Although some inhibitory factors of macrophages were identified in these analyses, ImmQuant analyses suggested no associations with immune responses (Figure 4).

Genome-wide association studies are commonly used to evaluate gene expression and mutations in GBM. However, comprehensive genetic data from whole-genome sequencing, whole-exome analyses, DNA-methylation analyses, and DNA microarrays do not necessarily coincide with phenotypes. In addition, other analysis types, such as analyses of molecular mechanisms, pathway analysis, proteomics, and metabolomics, are not well integrated. Our novel cellular bioinformatics pipeline for cancer research addresses these limitations of previous approaches.

The human glioma cell line U251 has contributed substantially to GBM research. However, its gene-expression profiles differ from those of GBM tissues (33). To clarify this point, we performed PCA analyses and factor loading using microarray data obtained from GSCs, U251, and hGBM (Figures 1A and 2). These analyses revealed substantial differences in the gene-expression patterns of GSCs, U251, and GBM. PC1 reflected the characteristics of cell lines; PC2 reflected the characteristics of stemness. Since the characteristics of stemness are thought to be important for GSC identification in heterogeneous environments, such as GBM tissues, we directed our focus to the factors contributing to PC2.

We identified $M Y C N$ as a representative factor for the stemness of GSCs. MYCN is a member of the Myc family of oncogenes. It is related to cell proliferation and apoptosis regulation. A pathway analysis revealed that MYCN is involved in the remarkable changes in the miR target genes in lymphocyte pathways. MYCN is a major determinant of cell division and transcription amplification $(34,35)$ and is highly expressed in children and young patients with GBM with the H3F3A G34 mutation occurring in the forebrain (36).

$D P P 4$, a well-known target for diabetes mellitus treatment, was also identified as a representative factor for the stemness 
of GSCs in this study. DPP4 is involved in several signaling pathways, such as PI3K signaling, RAS signaling, and mitogen-activated protein kinase signaling via glucagon-like peptide-1 $(37,38)$. Consistent with this, the pathway analyses in this study suggested substantial differences in the PI3K and RAS pathways (Figure 3). The continued administration of the DPP4 inhibitor sitagliptin inhibited the carcinogenesis of 1,2dimethylhydrazine-induced colon cancer (39). DPP4 also acts as a serine exopeptidase with dipeptidyl peptidase activity and thereby regulates various physiological processes by cleaving circulating peptides, including many chemokines, mitogenic growth factors, neuropeptides, and peptide hormones. DPP4 appears to be associated with malignant tumor development and progression by both enzymatic and nonenzymatic mechanisms $(40,41)$. Taken together, these data show DPP4 might be involved in glucose metabolism in GSCs for survival even under stress.

The factor loadings for PC1 indicated that GULP1, EYA4, $S T K 26$, and SEMA3A are markers to distinguish cultured cells (GSCs and U251) from GBM (Figure 2A). Among these genes, EYA4 and STK26 are related to the aggressiveness of GBM. EYA4 is involved in DNA repair, apoptosis, and innate immunity following DNA damage and cellular damage. STK26 is involved in cell growth, autophagy, and tumorigenicity $(42,43)$. SEMA3A is highly expressed in GBM, and the SEMA3A signaling axis promotes GBM growth and invasion (44). SEMA3A is also highly expressed in the breast cancer stem line MCF-7 (45) and the hepatocellular carcinoma cell line MHCC97H (46). In contrast, GULPl is thought to act as a cancer suppressor (47). In contrast, complement C1q C chain (C1QC), olfactomedin 1 (OLFMI), G protein-coupled receptor 17 (GPR17), family with sequence similarity 107 member A (FAM107A); neuronal pentraxin 2 (NPTX2), regulator of $\mathrm{G}$ protein signaling $1(R G S 1)$, aquaporin $4(A Q P 4)$, peripheral myelin protein $2(P M P 2)$, glutamate ionotropic receptor AMPA type subunit 2 (GRIA2), and neurotrophic receptor tyrosine kinase 2 (NTRK2) appeared to contribute negatively to PC1 (Figure 2A). Given that these genes, except for $C 1 Q C, R G S 1$, and $A Q A 4$, are found in normal brain tissues (48), PC1 likely reflects the differences between cell lines (GSCs and U251) and tissue-derived materials (GBM). Their biological functions should be elucidated in future studies.

The factor loadings for PC2 also identified two macrophageinhibitory factors (Figure 2B). One was $M I F$, which encodes a lymphokine involved in cell-mediated immunity, immunoregulation, and inflammation (49). MIF expression in GSCs appears to be involved in the immunotolerance of GBM by activating the immunosuppressive cell population (50). The amplification of $M I F$ is also related to cell proliferation and differentiation (51). ImmQuant analyses suggested no changes in macrophages or dendritic cells. The involvement of naïve $\mathrm{CD}^{+}{ }^{+} \mathrm{T}$-cells and naïve $\mathrm{CD}^{+} \mathrm{T}$-cells was suggested. To elucidate precise immune responses, it is necessary to coculture the tumor cells with immune cells or treat cells with GBM-related cytokines.

The pathway analyses revealed the remarkable enrichment of gene expression in GSCs against GBM as a control (Figure 3), consistent with previous results $(14,27,52,53)$. The genes were related to the PI3K-AKT signaling pathway, MAPK signaling pathway, RAS signaling, and other survival signals and growth signals, all of which are associated with proliferation, survival, glucose metabolism, and protein synthesis signaling (54-56).

Validation experiments are indispensable in confirming the results of transomics studies (57), which we intentionally omitted from this study. We are in the process of including validation experiments in the analysis pipeline. In particular, further studies are needed to verify the associations of $M Y C N$ and DPP4 with GSCs. We observed substantial differences in gene expression between GSCs and GBM. The differences are expected because GSC lines are a collection of single cells, whereas patient GBM tissues are aggregates of various cells. In study to highlight the characteristics of tumor cells, other methods should be considered in order to extract tumor cells more precisely from surgical specimens, such as a laser capture microdissection method.

\section{Conclusion}

We established a novel cellular bioinformatics pipeline consisting of a PCA with factor loading, intracellular pathway analysis, and immunological pathway analysis using microarray data. PCA mapping revealed clear differences in gene expression among GSCs, GBM tissue, and U251. Factor loadings revealed that the representative factors in GSCs are related to cell proliferation (MYCN and DPP4). The pathway analysis revealed that the PI3K-AKT signaling pathway was enriched in GSCs. Here, MYCN and DPP4 was shown to be related to the stemness of GSCs, and the PI3KAKT signaling pathway has been shown to be important for cellular processes in GSCs. The cellular bioinformatics pipeline is a useful method for clarifying the similarities and differences among cell populations and collections.

\section{Conflicts of Interest}

The Authors declare no conflicts of interest regarding this study.

\section{Authors' Contributions}

Conceptualization: DS, TT and SY; Methodology: DS, TT and MF; Software: DS, TT and SO; Validation: MF and SY; Formal analysis: MF; Investigation: DS and TT; Resources: DS, TT, YY and TI; Data curation: DS and TT; Writing-original draft preparation: DS; Writing-review and editing: TT, MF and SY; Visualization: DS and TT; Supervision: SY; Project administration: TT and SY. 


\section{Acknowledgements}

This work was supported by MEXT KAKENHI Grant Numbers JP15K10348 (M.F.) and JP18K09012 (M.F.). The Authors gratefully thank Professor Ikuo Tsunoda at Kindai University for giving us excellent advice as to data analysis. We also acknowledge the excellent technical assistance of Ms. Makiko Murase and Ms. Yuki Takeda.

\section{References}

1 Stupp R, Hegi ME, Mason WP, van den Bent MJ, Taphoorn MJ, Janzer RC, Ludwin SK, Allgeier A, Fisher B, Belanger K, Hau P, Brandes AA, Gijtenbeek J, Marosi C, Vecht CJ, Mokhtari K, Wesseling P, Villa S, Eisenhauer E, Gorlia T, Weller M, Lacombe D, Cairncross JG, Mirimanoff RO; European Organisation for Resarch and Treatment of Cancer Brain Tumour and Radiation Oncology Groups; National Cancer Institute of Canada Clinical Trials Group: Effects of radiotherapy with concomitant and adjuvant temozolomide versus radiotherapy alone on survival in glioblastoma in a randomised phase III study: 5-year analysis of the EORTC-NCIC trial. Lancet Oncol 10(5): 459-466, 2009. PMID: 19269895, DOI: 10.1016/S14702045(09)70025-7

2 Schonberg DL, Lubelski D, Miller TE and Rich JN: Brain tumor stem cells: Molecular characteristics and their impact on therapy. Mol Aspects Med 39: 82-101, 2014. PMID: 23831316, DOI: 10.1016/j.mam.2013.06.004

3 Iwadate Y: Plasticity in glioma stem cell phenotype and its therapeutic implication. Neurol Med Chir 58(2): 61-70, 2018. PMID: 29129882, DOI: 10.2176/nmc.ra.2017-0089

4 Venere M, Fine HA, Dirks PB and Rich JN: Cancer stem cells in gliomas: Identifying and understanding the apex cell in cancer's hierarchy. Glia 59(8): 1148-1154, 2011. PMID: 21547954, DOI: $10.1002 /$ glia.21185

5 Anido J, Saez-Borderias A, Gonzalez-Junca A, Rodon L, Folch G, Carmona MA, Prieto-Sanchez RM, Barba I, Martinez-Saez E, Prudkin L, Cuartas I, Raventos C, Martinez-Ricarte F, Poca MA, Garcia-Dorado D, Lahn MM, Yingling JM, Rodon J, Sahuquillo J, Baselga J and Seoane J: TGF- $\beta$ receptor inhibitors target the CD44(high)/ID1(high) glioma-initiating cell population in human glioblastoma. Cancer Cell 18(6): 655-668, 2010. PMID: 21156287, DOI: 10.1016/j.ccr.2010.10.023

6 Bao S, Wu Q, McLendon RE, Hao Y, Shi Q, Hjelmeland AB, Dewhirst MW, Bigner DD and Rich JN: Glioma stem cells promote radioresistance by preferential activation of the DNA damage response. Nature 444(7120): 756-760, 2006. PMID: 17051156, DOI: 10.1038/nature05236

7 Singh SK, Clarke ID, Hide T and Dirks PB: Cancer stem cells in nervous system tumors. Oncogene 23(43): 7267-7273, 2004. PMID: 15378086, DOI: 10.1038/sj.onc.1207946

8 Singh SK, Clarke ID, Terasaki M, Bonn VE, Hawkins C, Squire $\mathrm{J}$ and Dirks PB: Identification of a cancer stem cell in human brain tumors. Cancer Res 63(18): 5821-5828, 2003. PMID: 14522905

9 Soeda A, Hara A, Kunisada T, Yoshimura S, Iwama T and Park DM: The evidence of glioblastoma heterogeneity. Sci Rep 5: 7979, 2015. PMID: 25623281, DOI: 10.1038/srep07979

10 Jayaram S, Gupta MK, Raju R, Gautam P and Sirdeshmukh R: Multi-omics data integration and mapping of altered kinases to pathways reveal gonadotropin hormone signaling in glioblastoma. OMICS 20(12): 736-746, 2016. PMID: 27930095, DOI: $10.1089 /$ omi.2016.0142

11 Hegi ME, Diserens AC, Gorlia T, Hamou MF, de Tribolet N, Weller M, Kros JM, Hainfellner JA, Mason W, Mariani L, Bromberg JE, Hau P, Mirimanoff RO, Cairncross JG, Janzer RC and Stupp R: $M G M T$ gene silencing and benefit from temozolomide in glioblastoma. N Engl J Med 352(10): 9971003, 2005. PMID: 15758010, DOI: 10.1056/NEJMoa043331

12 Yan H, Parsons DW, Jin G, McLendon R, Rasheed BA, Yuan W, Kos I, Batinic-Haberle I, Jones S, Riggins GJ, Friedman H, Friedman A, Reardon D, Herndon J, Kinzler KW, Velculescu VE, Vogelstein B and Bigner DD: $I D H 1$ and $I D H 2$ mutations in gliomas. N Engl J Med 360(8): 765-773, 2009. PMID: 19228619, DOI: 10.1056/NEJMoa0808710

13 Louis DN, Perry A, Reifenberger G, von Deimling A, FigarellaBranger D, Cavenee WK, Ohgaki H, Wiestler OD, Kleihues P and Ellison DW: The 2016 World Health Organization Classification of Tumors of the Central Nervous System: A summary. Acta Neuropathol 131(6): 803-820, 2016. PMID: 27157931, DOI: $10.1007 / \mathrm{s} 00401-016-1545-1$

14 Cancer Genome Atlas Research Network: Comprehensive genomic characterization defines human glioblastoma genes and core pathways. Nature 455(7216): 1061-1068, 2008. PMID: 18772890, DOI: $10.1038 /$ nature07385

15 Johnson AB, Denko N and Barton MC: Hypoxia induces a novel signature of chromatin modifications and global repression of transcription. Mutat Res 640(1-2): 174-179, 2008. PMID: 18294659, DOI: 10.1016/j.mrfmmm.2008.01.001

16 Shenouda SK and Alahari SK: MicroRNA function in cancer: Oncogene or a tumor suppressor? Cancer Metastasis Rev 28(34): 369-378, 2009. PMID: 20012925, DOI: 10.1007/s10555-0099188-5

17 Volinia S, Calin GA, Liu CG, Ambs S, Cimmino A, Petrocca F, Visone R, Iorio M, Roldo C, Ferracin M, Prueitt RL, Yanaihara N, Lanza G, Scarpa A, Vecchione A, Negrini M, Harris CC and Croce CM: A microRNA expression signature of human solid tumors defines cancer gene targets. Proc Natl Acad Sci USA 103(7): $2257-$ 2261, 2006. PMID: 16461460, DOI: $10.1073 /$ pnas.0510565103

18 Hambardzumyan D, Gutmann DH and Kettenmann H: The role of microglia and macrophages in glioma maintenance and progression. Nat Neurosci 19(1): 20-27, 2016. PMID: 26713745 , DOI: $10.1038 / \mathrm{nn} .4185$

19 Soeda A, Lathia J, Williams BJ, Wu Q, Gallagher J, AndroutsellisTheotokis A, Giles AJ, Yang C, Zhuang Z, Gilbert MR, Rich JN and Park DM: The p38 signaling pathway mediates quiescence of glioma stem cells by regulating epidermal growth factor receptor trafficking. Oncotarget 8(20): 33316-33328, 2017. PMID: 28410196, DOI: 10.18632 /oncotarget.16741

20 Soeda A, Park M, Lee D, Mintz A, Androutsellis-Theotokis A, McKay RD, Engh J, Iwama T, Kunisada T, Kassam AB, Pollack IF and Park DM: Hypoxia promotes expansion of the CD133positive glioma stem cells through activation of HIF-1alpha. Oncogene 28(45): 3949-3959, 2009. PMID: 19718046, DOI: 10.1038/onc. 2009.252

21 Oka N, Soeda A, Inagaki A, Onodera M, Maruyama H, Hara A, Kunisada $\mathrm{T}$, Mori $\mathrm{H}$ and Iwama $\mathrm{T}$ : VEGF promotes tumorigenesis and angiogenesis of human glioblastoma stem cells. Biochem Biophys Res Commun 360(3): 553-559, 2007. PMID: 17618600, DOI: 10.1016/j.bbrc.2007.06.094 
22 Sakuma R, Takahashi A, Nakano-Doi A, Sawada R, Kamachi S, Beppu M, Takagi T, Yoshimura S, Matsuyama T and Nakagomi $\mathrm{T}$ : Comparative characterization of ischemia-induced brain multipotent stem cells with mesenchymal stem cells: Similarities and differences. Stem Cells Dev 27(19): 1322-1338, 2018. PMID: 29999479, DOI: 10.1089/scd.2018.0075

23 Fan J, Liao Y and Wang W: Projected principal component analysis in factor models. Ann Stat 44(1): 219-254, 2016. PMID: 26783374, DOI: 10.1214/15-AOS1364

24 Omura S, Kawai E, Sato F, Martinez NE, Chaitanya GV, Rollyson PA, Cvek U, Trutschl M, Alexander JS and Tsunoda I: Bioinformatics multivariate analysis determined a set of phasespecific biomarker candidates in a novel mouse model for viral myocarditis. Circ Cardiovasc Genet 7(4): 444-454, 2014. PMID: 25031303, DOI: 10.1161/CIRCGENETICS.114.000505

25 Pico AR, Kelder T, van Iersel MP, Hanspers K, Conklin BR and Evelo C: Wikipathways: Pathway editing for the people. PLoS Biol 6(7): e184, 2008. PMID: 18651794, DOI: 10.1371/ journal.pbio.0060184

26 Frishberg A, Brodt A, Steuerman Y and Gat-Viks I: Immquant: A user-friendly tool for inferring immune cell-type composition from gene-expression data. Bioinformatics 32(24): 3842-3843, 2016. PMID: 27531105, DOI: 10.1093/bioinformatics/btw535

27 MAQC Consortium, Shi L, Reid LH, Jones WD, Shippy R, Warrington JA, Baker SC, Collins PJ, de Longueville F, Kawasaki ES, Lee KY, Luo Y, Sun YA, Willey JC, Setterquist RA, Fischer GM, Tong W, Dragan YP, Dix DJ, Frueh FW, Goodsaid FM, Herman D, Jensen RV, Johnson CD, Lobenhofer EK, Puri RK, Schrf U, Thierry-Mieg J, Wang C, Wilson M, Wolber PK, Zhang L, Amur S, Bao W, Barbacioru CC, Lucas AB, Bertholet V, Boysen C, Bromley B, Brown D, Brunner A, Canales R, Cao XM, Cebula TA, Chen JJ, Cheng J, Chu TM, Chudin E, Corson J, Corton JC, Croner LJ, Davies C, Davison TS, Delenstarr G, Deng X, Dorris D, Eklund AC, Fan XH, Fang H, Fulmer-Smentek S, Fuscoe JC, Gallagher K, Ge W, Guo L, Guo X, Hager J, Haje PK, Han J, Han T, Harbottle HC, Harris SC, Hatchwell E, Hauser CA, Hester S, Hong H, Hurban P, Jackson SA, Ji H, Knight CR, Kuo WP, LeClerc JE, Levy S, Li QZ, Liu C, Liu Y, Lombardi MJ, Ma Y, Magnuson SR, Maqsodi B, McDaniel T, Mei N, Myklebost O, Ning B, Novoradovskaya N, Orr MS, Osborn TW, Papallo A, Patterson TA, Perkins RG, Peters EH, Peterson R, Philips KL, Pine PS, Pusztai L, Qian F, Ren H, Rosen M, Rosenzweig BA, Samaha RR, Schena M, Schroth GP, Shchegrova S, Smith DD, Staedtler F, Su Z, Sun H, Szallasi Z, Tezak Z, Thierry-Mieg D, Thompson KL, Tikhonova I, Turpaz Y, Vallanat B, Van C, Walker SJ, Wang SJ, Wang Y, Wolfinger R, Wong A, Wu J, Xiao C, Xie Q, Xu J, Yang W, Zhang L, Zhong S, Zong Y and Slikker W Jr.: The MicroArray Quality Control (MAQC) project shows interand intraplatform reproducibility of gene expression measurements. Nat Biotechnol 24(9): 1151-1161, 2006. PMID: 16964229, DOI: $10.1038 /$ nbt1239

28 Sun P, Xia S, Lal B, Eberhart CG, Quinones-Hinojosa A, Maciaczyk J, Matsui W, Dimeco F, Piccirillo SM, Vescovi AL and Laterra J: DNER, an epigenetically modulated gene, regulates glioblastoma-derived neurosphere cell differentiation and tumor propagation. Stem Cells 27(7): 1473-1486, 2009. PMID: 19544453, DOI: $10.1002 /$ stem.89

29 Verhaak RG, Hoadley KA, Purdom E, Wang V, Qi Y, Wilkerson MD, Miller CR, Ding L, Golub T, Mesirov JP, Alexe G, Lawrence M, O'Kelly M, Tamayo P, Weir BA, Gabriel S,
Winckler W, Gupta S, Jakkula L, Feiler HS, Hodgson JG, James CD, Sarkaria JN, Brennan C, Kahn A, Spellman PT, Wilson RK, Speed TP, Gray JW, Meyerson M, Getz G, Perou CM, Hayes DN and Cancer Genome Atlas Research Network: Integrated genomic analysis identifies clinically relevant subtypes of glioblastoma characterized by abnormalities in PDGFRA, IDH1, EGFR, and NF1. Cancer Cell 17(1): 98-110, 2010. PMID: 20129251, DOI: 10.1016/j.ccr.2009.12.020

30 Zhao K, Wang Q, Wang Y, Huang K, Yang C, Li Y, Yi K and Kang C: EGFR/c-myc axis regulates TGF//Hippo/Notch pathway via epigenetic silencing miR-524 in gliomas. Cancer Lett 406: 1221, 2017. PMID: 28778566, DOI: 10.1016/j.canlet.2017.07.022

31 Zheng H, Ying H, Yan H, Kimmelman AC, Hiller DJ, Chen AJ, Perry SR, Tonon G, Chu GC, Ding Z, Stommel JM, Dunn KL, Wiedemeyer R, You MJ, Brennan C, Wang YA, Ligon KL, Wong WH, Chin L and DePinho RA: P53 and PTEN control neural and glioma stem/progenitor cell renewal and differentiation. Nature 455(7216): 1129-1133, 2008. PMID: 18948956, DOI: 10.1038/nature07443

32 Guerrero PA, Yin W, Camacho L and Marchetti D: Oncogenic role of Merlin/NF2 in glioblastoma. Oncogene 34(20): 26212630, 2015. PMID: 25043298, DOI: 10.1038/onc.2014.185

33 Hess KR, Fuller GN, Rhee CH and Zhang W: Statistical pattern analysis of gene expression profiles for glioblastoma tissues and cell lines. Int J Mol Med 8(2): 183-188, 2001. PMID: 11445872

34 Wang J, Wang $\mathrm{H}$, Li Z, Wu Q, Lathia JD, McLendon RE, Hjelmeland $\mathrm{AB}$ and Rich JN: c-MYC is required for maintenance of glioma cancer stem cells. PLoS One 3(11): e3769, 2008. PMID: 19020659, DOI: 10.1371/journal.pone. 0003769

35 Topham C, Tighe A, Ly P, Bennett A, Sloss O, Nelson L, Ridgway RA, Huels D, Littler S, Schandl C, Sun Y, Bechi B, Procter DJ, Sansom OJ, Cleveland DW and Taylor SS: MYC Is a major determinant of mitotic cell fate. Cancer Cell 28(1): 129140, 2015. PMID: 26175417, DOI: 10.1016/j.ccell.2015.06.001

36 Bjerke L, Mackay A, Nandhabalan M, Burford A, Jury A, Popov S, Bax DA, Carvalho D, Taylor KR, Vinci M, Bajrami I, McGonnell IM, Lord CJ, Reis RM, Hargrave D, Ashworth A, Workman P and Jones C: Histone H3.3. mutations drive pediatric glioblastoma through up-regulation of MYCN. Cancer Discov 3(5): 512-519, 2013. PMID: 23539269, DOI: 10.1158/2159-8290.CD-12-0426

37 Bohm A, Wagner R, Machicao F, Holst JJ, Gallwitz B, Stefan $\mathrm{N}$, Fritsche A, Haring HU and Staiger H: DPP4 gene variation affects GLP-1 secretion, insulin secretion, and glucose tolerance in humans with high body adiposity. PLoS One 12(7): e0181880, 2017. PMID: 28750074, DOI: 10.1371/journal.pone.0181880

38 Zhu H, Zhang Y, Shi Z, Lu D, Li T, Ding Y, Ruan Y and Xu A: The neuroprotection of liraglutide against ischaemia-induced apoptosis through the activation of the PI3K/AKT and MAPK pathways. Sci Rep 6: 26859, 2016. PMID: 27240461, DOI: 10.1038/srep26859

39 Femia AP, Raimondi L, Maglieri G, Lodovici M, Mannucci E and Caderni G: Long-term treatment with Sitagliptin, a dipeptidyl peptidase- 4 inhibitor, reduces colon carcinogenesis and reactive oxygen species in 1,2-dimethylhydrazine-induced rats. Int J Cancer 133(10): 2498-2503, 2013. PMID: 23649733, DOI: $10.1002 / \mathrm{ijc} .28260$

40 Busek P, Stremenova J, Sromova L, Hilser M, Balaziova E, Kosek D, Trylcova J, Strnad H, Krepela E and Sedo A: Dipeptidyl peptidase-IV inhibits glioma cell growth independent 
of its enzymatic activity. Int J Biochem Cell Biol 44(5): 738747, 2012. PMID: 22306301, DOI: 10.1016/j.biocel.2012.01.011

41 Busek P, Stremenova J, Krepela E and Sedo A: Modulation of substance $\mathrm{P}$ signaling by dipeptidyl peptidase-IV enzymatic activity in human glioma cell lines. Physiol Res 57(3): 443-449, 2008. PMID: 17949241

42 Thompson BJ and Sahai E: MST kinases in development and disease. J Cell Biol 210(6): 871-882, 2015. PMID26370497, DOI: $10.1083 /$ jcb.201507005

43 Osborn JW, Taylor RF and Schramm LP: Determinants of arterial pressure after chronic spinal transection in rats. Am J Physiol 256(3 Pt 2): R666-673, 1989. PMID: 2923255, DOI: 10.1152/ajpregu.1989.256.3.R666

44 Lee J, Shin YJ, Lee K, Cho HJ, Sa JK, Lee SY, Kim SH, Lee J, Yoon Y and Nam DH: Anti-SEMA3A antibody: A novel therapeutic agent to suppress glioblastoma tumor growth. Cancer Res Treat 50(3): 1009-1022, 2018. PMID: 29129044, DOI: $10.4143 /$ crt.2017.315

45 Shen WW, Chen WG, Liu FZ, Hu X, Wang HK, Zhang Y and Chu TW: Breast cancer cells promote osteoblastic differentiation via SEMA 3A signaling pathway in vitro. Int J Clin Exp Pathol 8(2): 1584-1593, 2015. PMID: 25973043

$46 \mathrm{Hu}$ ZQ, Zhou SL, Zhou ZJ, Luo CB, Chen EB, Zhan H, Wang PC, Dai Z, Zhou J, Fan J and Huang XW: Overexpression of semaphorin $3 \mathrm{~A}$ promotes tumor progression and predicts poor prognosis in hepatocellular carcinoma after curative resection. Oncotarget 7(32): 51733-51746, 2016. PMID: 27351132, DOI: 10.18632/oncotarget.10104

47 Maldonado L, Brait M, Izumchenko E, Begum S, Chatterjee A, Sen T, Loyo M, Barbosa A, Poeta ML, Makarev E, Zhavoronkov A, Fazio VM, Angioli R, Rabitti C, Ongenaert M, Van Criekinge W, Noordhuis MG, de Graeff P, Wisman GBA, van der Zee AGJ and Hoque MO: Integrated transcriptomic and epigenomic analysis of ovarian cancer reveals epigenetically silenced GULP1. Cancer Lett 433: 242-251, 2018. PMID: 29964205, DOI: $10.1016 /$ j.canlet.2018.06.030

48 Fagerberg L, Hallstrom BM, Oksvold P, Kampf C, Djureinovic D, Odeberg J, Habuka M, Tahmasebpoor S, Danielsson A, Edlund K, Asplund A, Sjostedt E, Lundberg E, Szigyarto CA, Skogs M, Takanen JO, Berling H, Tegel H, Mulder J, Nilsson P, Schwenk JM, Lindskog C, Danielsson F, Mardinoglu A, Sivertsson A, von Feilitzen K, Forsberg M, Zwahlen M, Olsson I, Navani S, Huss M, Nielsen J, Ponten F and Uhlen M: Analysis of the human tissue-specific expression by genome-wide integration of transcriptomics and antibody-based proteomics. Mol Cell Proteomics 13(2): 397-406, 2014. PMID: 24309898, DOI: $10.1074 / \mathrm{mcp} . M 113.035600$

49 Mitchell RA: Mechanisms and effectors of MIF-dependent promotion of tumourigenesis. Cell Signal 16(1): 13-19, 2004. PMID: 14607271

50 Otvos B, Silver DJ, Mulkearns-Hubert EE, Alvarado AG, Turaga SM, Sorensen MD, Rayman P, Flavahan WA, Hale JS, Stoltz K, Sinyuk M, Wu Q, Jarrar A, Kim SH, Fox PL, Nakano I, Rich JN, Ransohoff RM, Finke J, Kristensen BW, Vogelbaum MA and Lathia JD: Cancer stem cell-secreted macrophage migration inhibitory factor stimulates myeloid derived suppressor cell function and facilitates glioblastoma immune evasion. Stem Cells 34(8): 20262039, 2016. PMID: 27145382, DOI: 10.1002/stem.2393
51 Fukaya R, Ohta S, Yaguchi T, Matsuzaki Y, Sugihara E, Okano H, Saya H, Kawakami Y, Kawase T, Yoshida K and Toda M: MIF maintains the tumorigenic capacity of brain tumor-initiating cells by directly inhibiting p53. Cancer Res 76(9): 2813-2823, 2016. PMID: 26980763, DOI: 10.1158/0008-5472.CAN-15-1011

52 Muto J, Imai T, Ogawa D, Nishimoto Y, Okada Y, Mabuchi Y, Kawase T, Iwanami A, Mischel PS, Saya H, Yoshida K, Matsuzaki Y and Okano H: RNA-binding protein MUSASHI1 modulates glioma cell growth through the post-transcriptional regulation of NOTCH and PI3 kinase/AKT signaling pathways. PLoS One 7(3): e33431, 2012. PMID: 22428049, DOI: 10.1371/journal.pone.0033431

53 Sato A, Okada M, Shibuya K, Watanabe E, Seino S, Narita Y, Shibui S, Kayama T and Kitanaka C: Pivotal role for ROS activation of p38 MAPK in the control of differentiation and tumor-initiating capacity of glioma-initiating cells. Stem Cell Res 12(1): 119-131, 2014. PMID: 24185179, DOI: 10.1016/j.scr2013.09.012

54 Liao YX, Zhang ZP, Zhao J and Liu JP: Effects of fibronectin 1 on cell proliferation, senescence and apoptosis of human glioma cells through the PI3K/AKT signaling pathway. Cell Physiol Biochem 48(3): 1382-1396, 2018. PMID: 30048971, DOI: $10.1159 / 000492096$

55 Rodriguez-Garcia A, Samso P, Fontova P, Simon-Molas H, Manzano A, Castano E, Rosa JL, Martinez-Outshoorn U, Ventura F, Navarro-Sabate A and Bartrons R: TGF- $\beta 1$ targets SMAD, p38 MAPK, and PI3K/AKT signaling pathways to induce $P F K F B 3$ gene expression and glycolysis in glioblastoma cells. FEBS J 284(20): 3437-3454, 2017. PMID: 28834297 , DOI: $10.1111 /$ febs. 14201

56 Shingu T, Holmes L, Henry V, Wang Q, Latha K, Gururaj AE, Gibson LA, Doucette T, Lang FF, Rao G, Yuan L, Sulman EP, Farrell NP, Priebe W, Hess KR, Wang YA, Hu J and Bogler O: Suppression of RAF/MEK or PI3K synergizes cytotoxicity of receptor tyrosine kinase inhibitors in glioma tumor-initiating cells. J Transl Med 14: 46, 2016. PMID: 26861698, DOI: 10.1186/s12967-016-0803-2

57 Shen-Orr SS and Gaujoux R: Computational deconvolution: Extracting cell type-specific information from heterogeneous samples. Curr Opin Immunol 25(5): 571-578, 2013. PMID: 24148234, DOI: 10.1016/j.coi.2013.09.015
Received December 30, 2018

Revised January 19, 2019

Accepted January 22, 2019 